\title{
PENERAPAN METODE ANALISIS ABC DALAM PENGENDALIAN PERSEDIAN BAHAN BAKU PADA PT. DYRIANA (Cabang Gatot Subroto)
}

\author{
Dewi Nita Pratiwi ${ }^{1}$ \\ Saifudin ${ }^{2}$ \\ nithapratiwi18@gmail.com ${ }^{1}$ \\ saifudin@usm.ac.id ${ }^{2}$ \\ Fakultas Ekonomi Universitas Semarang
}

Diterima : November 2020, Disetujui : Desember 2020, Dipublikasikan: Januari 2021

\begin{abstract}
This research was conducted at PT. Dyriana Bakery in the warehouse of raw materials regarding the $A B C$ analysis method for controlling raw materials at PT. Dyriana Bakery, Gatot Subroto Branch. The purpose of this study is to improve the efficiency and effectiveness in planning raw material orders for the Gatot Subroto Branch warehouse.This research uses descriptive method, by analyzing data on the use of raw materials in 2019 as the source data obtained by the $A B C$ method formula to produce three categories based on category A, category $B$, and category $C$. Medium, and the lowest and the raw materials based on their use. The results of this study are components categorized into 3 with this $A B C$ analysis, it can be seen that the number of items included in category $A$ is 19 items or equal to 20 percent of the total items at a cost of $R p$ 3,848,136,214 or equal to 80 percent of Category $B$ A total of 25 items or equal to $26 \%$ of the total number of items at a cost of Rp. 770,801,302 or equal to $15 \%$, and for category $C$ a total of 51 items or equal to $54 \%$ of the items with a withdrawal fee of $R p .218,811,977$ or equal to 5 percent.
\end{abstract}

Keywords: preparation arrangements, ABC analysis methods, and preparation.

\begin{abstract}
ABSTRAK
Penelitian ini dilakukan di PT. Dyriana Bakery di bagian gudang bahan baku tentang penerapan metode analisis ABC pengendalian persedian bahan baku di PT. Dyriana Bakery Cabang Gatot Subroto. Tujuan penelitian ini adalah untuk meningkatkan efisiensi serta efektifitas dalam perencanaan order persediaan bahan baku untuk gudang Cabang Gatot Subroto.Penelitian ini menggunakan metode deskriptif, dengan menganalisis data pemakaian bahan baku pada tahun 2019 sebagai data sumbernya dioleh dengan rumus metode $\mathrm{ABC}$ sehingga menghasilkan tiga kategori yaitu kategori $\mathrm{A}$, kategori $\mathrm{B}$, dan kategori $\mathrm{C}$. Dengan metode $\mathrm{ABC}$ ini dapat diketahui bahan baku dengan investasi tertinggi, sedang, dan terendah serta perputaran bahan baku tersebut berdasarkan pemakaiannya. Hasil dari penelitian ini
\end{abstract}


adalah komponen-komponen dikategorikan menjadi 3 dengan analisis $\mathrm{ABC}$ tersebut, terlihat bahwa jumlah barang yang termasuk dalam kategori A sebanyak 19 item atau sama dengan 20 persen dari jumlah seluruh item dengan biaya sebesar Rp 3.848.136.214 atau sama dengan 80 persen dari penyerapan seluruh dana persediaan, sedangkan yang termasuk kategori B sebanyak 25 item atau sama dengan 26 persen dari jumlah seluruh barang dengan biaya penyerapan sebesar Rp 770.801.302 atau sama dengan 15 persen, dan untuk kategori $\mathrm{C}$ sebanyak 51 item atau sama dengan 54 persen dari jumlah barang dengan biaya penyerapan sebesar Rp 218.811.977 atau sama dengan 5 persen.

Kata kunci : pengendalian persediaan, metode analisis ABC, dan persediaan.

\section{PENDAHULUAN}

Sejalan perkembangan zaman dan kemajuan diberbagai bidang IPTEK dewasa ini sangat berpengaruh pada aktivitas kehidupan, diantaranya adalah dunia bisnis, terutama disektor pangan. Perusahaan lebih dituntut untuk bekerja dan berproduksi dengan lebih efisien dalam menghadapi persaingan yang lebih banyak untuk menjaga kelangsungan serta tujuan usaha bisnisnya yaitu laba. Proses pencapaian tujuan tersebut harus memperhatikan berbagai faktor. Faktor utama salah satunya yaitu bahan baku karena bagi perusahaan bahan baku merupakan hal penting dalam melakukan proses produksi. Oleh karena itu dibutuhkan penanganan yang baik pada bagian persedian bahan baku. Sehingga dengan pengendalian bahan baku akan mengendalikan pemborosan dana yang keluar dari kas perusahaan. Persedian bahan baku yang optimal bisa memperlancar proses produksi dan biaya dapat ditekan pada produk, untuk menjamin efisiensi dan efektifitas dari pemasaran. Menurut Bahagia (2006) didalam penelitian (Junaidi 2019) persedian adalah suatu sumber daya menganggur atau idle resources yang keberadaannya mengunggu proses lebih lanjut.

Dalam penelitian di Dyriana untuk saat ini sudah melakuan sistem untuk mengelola persediaan barang bahan baku yang telah diterima dari supplier walaupun secara manual dengan pencatatan di buku besar. Akan tetapi sistem tersebut hanya untuk mencatat persedian barang masuk dan barang yang keluar dari gudang saja sehingga tidak dapat memberikan informasi tentang barang yang paling banyak dibutuhkan, barang yang tidak banyak dibutuhkan, berapa banyak permintaan setiap pengguna, nama barang yang termasuk barang yang sulit untuk didapatkan dan yang lainnya. Padahal informasi tentang hal-hal tersebut sangat dibutuhkan oleh perusahaan Dyriana khususnya untuk mengelola persedian bahan baku agar kesiapan dalam proses produksi berjalan dengan lancar dan juga dana yang mengendap tidak terlalu banyak hanya untuk bahan baku saja.

Dilihat dari permasalahan yang terjadi di dalam perusahaan Dyriana ini maka akan menerapkan metode analisis ABC untuk menentukan ketersedian barang yang ada di dalam gudang. Karena pengklasifikasian ini bertujuan untuk mengetahui prioritas tiap kelompok item persediaan agar dapat menerapkan strategi pengelola persediaan yang sesuai dengan karakteristik persediaan. 
Analisis $\mathrm{ABC}$ adalah salah satu metode pengklasifikasian barang berdasarkan peringkat nilai dari nilai tertinggi hingga terendah, dan di bagi menjadi tiga kelompok yaitu kelompok A, kelompok B, dan kelompok C. Dengan mengetahui kriteria maring-masing kelas, dapat diketahui barang persediaan mana yang harus mendapat perhatian khusus atau hanya sekedar mengecek sesekali saja. Oleh sebab itu dapat diketahui bahwa kegiatan opersional perusahaaan diperlukan pengendalian persediaan agar bisa mengantisipasi resiko, sehingga terhentinya kegiatan proses produksi dan juga hilangnya pelanggan dikarena tidak persediaan bahan baku untuk itu maka kegiatan usahan ini dapat menggunakan metode ABC. Sehingga penulis tertarik untuk meneliti penelitian dengan judul "PENERAPAN METODE ANALISIS ABC DALAM PENGENDALIAN PERSEDIAAN BAHAN BAKU PADA PT. DYRIANA (Cabang Gatot Subroto)"

Adapun perumusan masalah dalam penelitian ini adalah: Berapa jumlah valime permintaan dan harga bahan baku di PT. Dyriana dan Bagaimana penerapan analisis ABC dalam pengendalian persediaan yang digunakan dalam pengelompokan bahan baku.

\section{TINJAUAN PUSTAKA}

\section{Akuntansi Managemen}

Menurut Tunggal (2011) dalam penelitian (Rotikan 2013), mendefinisikan akuntansi manajemen adalah pengidentifikasi, pengukuran, pengumpulan, penganalisasian, penyiapan, penafsiran, dan pengkomunikasian informasi yang dapat membantu para eksekutif dalam mencapai sasaran organisasi. Dari proses tersebut akan membantu perusahaan dalam mencapai tujuan utamanya.

\section{Persediaan}

\section{Pengertian Persediaan}

PSAK No. 14 (2007) mengartikan persediaan sebagai semua barang yang dimiliki perusahaan untuk dijual dalam kegiatan operasional perusahaan, barang dalam proses produksi, serta perlengkapan yang digunakan dalam proses produksi dan pemberian jasa. Persedian adalah aktiva lanca dalam perusahaan berupa bahan atau barang dengan nilai yang cukup tinggi, yang bisa di manfaatkan untuk dijual kembali secara langsung atau dimasukkan dalam proses produksi tergantung perusahaan tersebut. Jenis persediaan yang terdapat dalam sebuah perusahaan tergantung dari bentuk perusahaan tersebut. Dalam perusahaan dagang hanya ada satu macam persediaan, yaitu persediaan barang dagang. Sedangkan dalam perusahaan manufaktur terdapat tiga jenis persediaan, yaitu persedian bahan baku, persediaan barang dalam proses, dan persediaan barang jadi (Maisaroh, Sholihin, and Farhana 2019).

\section{Fungsi Persediaan}

Menurut Handoko (1999) efisiensi operasional suatu organisasi dapat ditingkatkan karena berbagai fungsi penting persediaan, antara lain:

\section{a. Fungsi Decoupling}



b. Fungsi Economic Lot Sizing
c. Fungsi Antisipasi

\section{Jenis Persediaan}

Menurut Prasetyawan dan Nasution (2008) menurut jenisnya, persediaan dapat dibedakan atas:
a. Bahan baku (raw material).
b. Bahan setengah jadi (work in process).
c. Bahan jadi (finished goods).
d. Bahan-bahan pembantu (supplier).

\section{Biaya Persediaan}

Menurut Handoko (1999) dalam pembuatan setiap keputusan yang akan menpengaruhi besarnya persediaan, biaya-biaya variabel berikut ini harus dipertimbangkan:
a. Biaya penyimpanan
b. Biaya pemesanan atau pemebelian
c. Biaya penyiapan
d. Biaya kehabisan atau kekurangan bahan

\section{Persedian Bahan Baku}

\section{Pengertian Bahan Baku}

Menurut Heizer dan Rebder (2010), persediaan adalah satu aset termahal dari banyak perusahan, mewakili sebanyak 50 persen dari keseluruhan modal yang diinvestasikan. Di satu sisi, sebah perusahaan dapat mengurangi biaya dengan mengrangi persediaan. Di sisi lain, produk dapat berhenti dan pelanggan menjadi tidak puas ketika sebuah barang tidak tersedia (Heizer dan Render, 2010 dalam penelitian (Junaidi 2019)).

\section{Arti Penting Bahan Baku}

Menurut Ahyari (1992) beberapa hal yang menyebabkan perusahaan harus menyelenggarakan persediaan bahan baku antara lain sebagai berikut:

1) Bahan baku yang pergunakan untuk proses produksi dalam perusahaan, tidak dapat di datangkan atau dibeli secara satu persatu sebesar jumlah yang diperlukan serta pada saat bahan tersebut digunakan.

2) Apabila terjadi bahan baku belum atau tidak ada persediaan, sedangkan bahan baku yang dipesan belum datang maka kegiatan proses produksi akan terhenti karena tidak ada bahan baku untuk kegiatan proses produksi.

3) Persediaan bahan yang terlalu besar tidak akan menguntungkan perusahaan. Persediaan yang terlalu besar ini akan menyerap dana perusahaan yang cukup besar serta semakin tingginya resiko kerusakan bahan, resiko kecurian dan sebaginya. 


\section{Pengendalian Persediaan}

\section{Pengertian Pengendalian Persediaan}

Menurut Herjanto (2008), pengendalian persediaan adalah serangkaian kebijakan pengendalian untuk menentukan tingkat persediaan yang harus dijaga, kapan pesanan untuk menambah persediaan harus dilakukan dan berapa besar pesananan harus diadakan, jumlah atau tingkat persediaan yang dibutuhkan berbeda-beda untuk setiap perusahaan, tergantung dari volume produksinya (Herjanto, 2008 dalam penelitiian (Analisis et al. 2015)).

\section{Fungsi dan Tujuan Pengendalian Persediaan}

Pengendalian persediaan juga berfungsi untuk memastikan barang persediaan di dalam perusahaan tidak kehabisan yang dapat mangakibatkan terhentinya proses produksi dan agar perusahaan selalu mempunyai persediaan dengan jumlah yang tepat, pada waktu yang tepat, dan dalam mutu yang baik sehingga usaha yang telah dijalankan tidak terganggu serta pengeluaran untuk biaya persediaan efektif.

\section{Analisis Activity Based Costing}

Menurut Bahagia (2006), pada prinsipnya analisis ABC adalah mengklasifikasikan jenis barang yang didasarkan atas tingkat investasi tahunan yang terserap di dalam penyediaan persediaan untuk setiap jenis barang (Bahagia, 2006 dalam penelitian (Suhara 2017)).

Berdasarkan prinsip Pareto, barang dapat diklasifikasikan menjadi tiga kategori yaitu:

1. Kategori A, menyerap dnri total modal yang tesedia sekitar 80 persen dari total modal yang tersedia untuk inventory dan jumlah jenis barangnya sektar 20 persen dari jenis barang yang dikelola.

2. Kategori B, menyerap dana sekitar 15 persen dari total modal yang tersedia untuk inventory dan jumlah jenis barangnya sekitar 30 persen dari semua jenis barang yang dikelola.

3. Kategori $\mathrm{C}$, menyerap dana hanya 5 persen dari total modal yang tersedia untuk inventory dan jumlah jenis barang sekitar 50 persen dari semua jenis barang yang dikelola.

\section{Hasil Penelitian Sebelumnya}

1. Junaidi (2019) dalam penelitiannya, "Penerapan Metode ABC Terhadap Pengendalian Persedian Bahan Baku Pada UD. Mayong Sari Probolinggo”. Dalam penelitian ini klasifikasi $\mathrm{ABC}$ yang dilakukan dapat mengetahui tingkat kepentingan barang bisa ditinjau dari tingkat kecepatan pemakaian, atau tingkat keuntungan yang dapat diperoleh dan berdasarkan tingkat penyerapam modal. Sehingga bahan baku yang masuk kategori A yaitu paling menyerap dana terbesar.

2. Happy Fauzi Afianti dan Hery Hamdi Azwir (2017) dalam penelitiannya. ', Pengendalian Persediaan Dan Penjadwalan Pasokan Bahan Baku Impor dengan Metode ABC Analysis di PT Unilever Indonesia, Cikarang, Jawa Barat". Dari hasil penelitian ini metode analisis ABC yang dilakukan berpengaruh terhadap efektifitas pembelian. 


\section{Alur Penelitian}

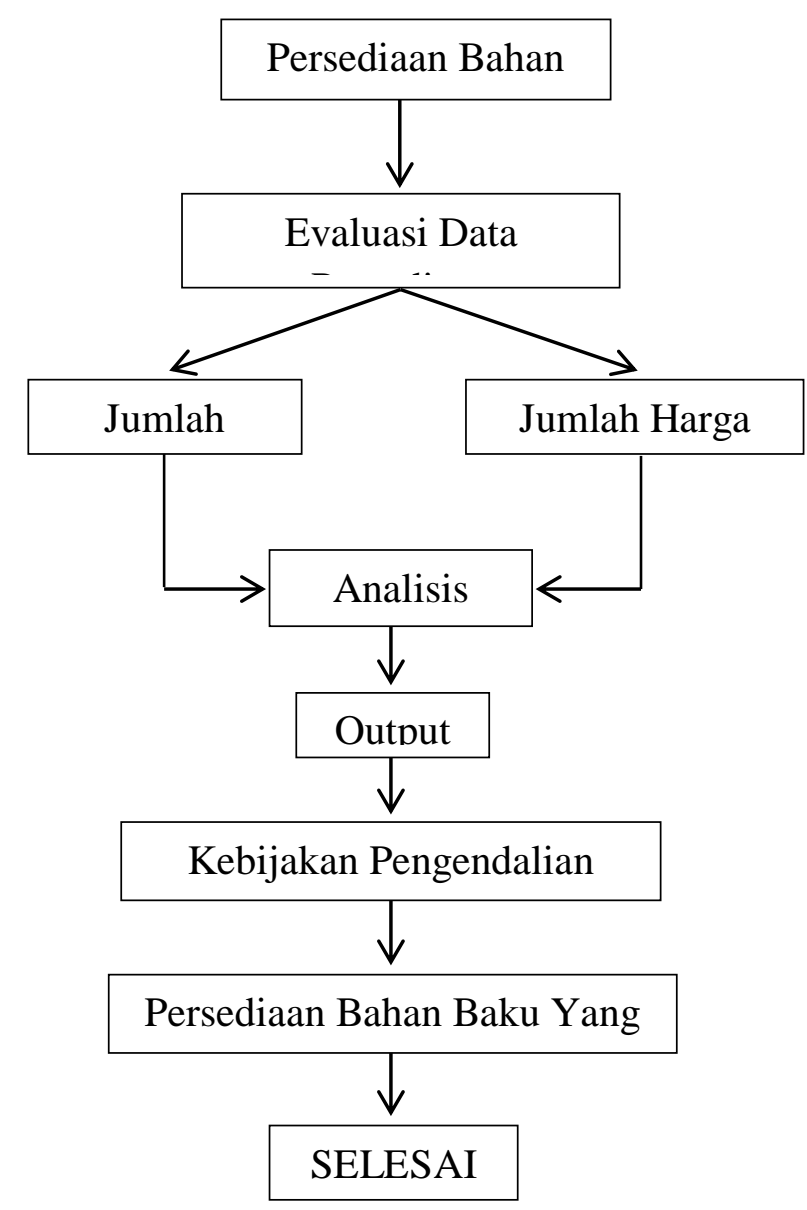

\section{METODE PENELITIAN}

\section{Jenis Penelitian}

Dalam penelitian ini menggunakan jenis penelitian yaitu Deskriptif. Penelitian deskriptif adalah salah satu jenis penelitian yang tujuannya untuk menyajikan gambaran lengkap untuk eksplorasi dan klarifikasi mengenai fenomena-fenomena yang ada, dengan jalan mendeskripsikan variabel yang ada dengan masalah dan unit yang diteliti antara fenomena yang diuji.

\section{Jenis Data Penelitian}

Data primer yaitu data yang berasal langsung dari sumber data yang dikumpulkan secara khusus dan berhubungan langsung dengan permasalahan yang diteliti. Jadi data primer dari penelitian ini adalah data yang diambil atau diperoleh langsung dari karyawan di perusahaan Dyriana melalui wawancara. 
Data sekunder adalah data yang sumbernya secara tidak langsung memberikan data kepada pengumpul data atau data yang diperoleh dari hasil laporan maupun catatan dokumentasi yang dimiliki perusahan.

\section{Tempat dan Waktu Penelitian \\ Tempat penelitian}

Penelitian ini dilakukan di PT Dyriana Cabang Gatot Subroto yang berlokasi di Kawasan Industri Candi, Gatot Subroto, Semarang Barat. Tempat ini dipilih karena merupakan tempat saya bekerja dan juga terdapat permasalahan dalam persediaan bahan baku yang harus diteliti lebih lanjut.

\section{Waktu penelitian}

Penelitian ini dilakukan di PT Dyriana Cabang Gatot Subroto pada tanggal 10 Otkober sampai 20 Oktober 2019.

\section{Subyek dan Obyek Penelitian}

Subyek penelitian adalah orang yang dijadikan sebagai sumber data atau sumber informasi oleh penelitian untuk riset yang dilakukan. Dan untuk obyek penelitian adalah masalah, isu dan problem yang dibahas, diteliti dan diselidiki dalam riset sosial. Jadi subyek dari penelitian ini yaitu PT Dyriana Cabang Gatot Subroto yang bergerak dalam bidang pangan tepatnya pengolahan roti. Sedangkan untuk obyek penelitian dalam penelitian yaitu persediaan bahan baku yang terdapat di PT Dyriana Cabang Gatot Subroto.

\section{Metode Pengumpulan Data}

Metode pengumpulan data berupa suatu perantaraan tentang sifat, keadaan, kegiatan tertentu dan sejenisnya. Pengumpulan data dilakukan untuk mendapatkan suatu informasi yang dibutuhkan dalam mencapai tujuan penelitian. Metode pengumpulan data yang digunakan dalam penelitian ini yaitu: wawancara, observasi, dan dokumentasi.

\section{Teknik Analisis Data}

Setelah data terkumpul maka langkah selanjutnya adalah menganalisis data, sehingga data tersebut dapat ditarik suatu kesimpulan. Teknik analisis data ini terdiri dari uji kredibilitas dan narasi data.

\section{Uji Kredibilitas Data}

Uji kredibilitas data dalam penelitian ini menggunakan teknik triangulasi. Triangulasi adalah teknik pengujian kredibilitas data yang memanfaatkan sesuatu yang lain diluar data itu untuk keperluan pengecekan atau sebagai pembanding terhadap data itu. Teknik trigulasi yang digunakan dalam penelitian ini adalah triangulasi sumber dan triangulasi metode.

A. Triangulasi sumber

Triangulasi sumber adalah langkah pengecekan kembali data-data yang diperoleh dari informan dengan cara membandingkan data atau informasi yang 
diperoleh dari informan kunci dengan informan pendukung. Seperti dilakukannya participant obervation, arsip, dokumen sejarah, catatan resmi, gambar dan catatan lainnya.

B. Tiangulasi Metode

Tiangulasi metode yaitu dengan melakukan pengecekan data penelitian dengan teknik pengumpulan data yang berbeda yakni wawancara, observasi, dan dokumentasi sehingga data bersifat kredibel. Seperti di PT. Dyriana dari hasil wawancara pada salah satu karyawan bagian gudang yang didapat menyatakan bahwa perusahaaan tersebut belum menggunakan metode analisis $\mathrm{ABC}$ sehingga kurang efektif dalam pengendalian persediaan bahan bakunya.

\section{Narasi Data}

Dalam penelitian ini apabila data dinilai kredibel, maka selanjutnya penelitian menarasikan data tersebut sesuai aspek yang diteliti. Narasi data dalam penelitian ini menggambarkan suatu obyek yaitu penelitian ini, mengunakan analisis kuantitatif karena data penelitian ini berupa angka-angka. Teknik analisis kuantitatif digunakan untuk mengetahui berapa besar pemakaian bahan baku. Selain itu analisis kuantitatif juga digunakan untuk mencari dana yang digunakan untuk suatu barang yang selanjutnya digunkan untuk menganalisis berdasarkan analisis ABC.

Langkah-langkah atau prosedur klasifikasi barang dalam analisis $\mathrm{ABC}$ sebagai berikut:

a. Mengidentifikasi produk yang ada di PT Dyriana.

b. Menentukan harga per unit dan volume kebutuhan per tahun.

c. Mengalikan harga per unit dengan volume kebutuhan untuk mentukan total nilai rupiah dari masing-masing barang.

Volume tahunan (dalam unit) $x$ harga per item

d. Menyusun urutan tipe barang menurut besarnya total nilai rupiah, dengan urutan pertama tipe barang dengan total nilai rupiah yang paling besar.

e. Menghitung nilai kumulatif barang.

f. Menghitung presentase kumulatif nilai rupiah.

Volume tahunan dalam nilai uang per unit $x 100 \%$

Jumlah penyerapan dana dalam setahun

g. Menggolongkan persedian ke dalam kelompok A, B, dan C.

\section{HASIL PENELITIAN DAN PEMBAHASAN}

\section{Analisis Data}

Pada bagian ini akan dilakukan pengolahan data setelah data-data yang diperlukan sudah diperoleh. Hal ini untuk mengetahui hasil dari tujuan penelitian yang selanjutnya akan dianalisis. Langkah-langkahnya sebagai berikut: 
Tabel 1Hasil Perhitungan Menggunakan Metode Analisis ABC

\begin{tabular}{|c|c|c|c|c|c|c|c|c|}
\hline No & $\begin{array}{l}\text { Nama } \\
\text { Barang }\end{array}$ & $\begin{array}{l}\text { Volume } \\
\text { Pemakaian } \\
\text { (Unit) }\end{array}$ & $\begin{array}{l}\text { Harga } \\
\text { (unit) }\end{array}$ & $\begin{array}{l}\text { Volume } \\
\text { Tahunan } \\
\text { (Rupiah) }\end{array}$ & $\begin{array}{l}\text { Nilai Kumulatif } \\
\text { (Rupiah) }\end{array}$ & $\begin{array}{c}\text { Penyerapan } \\
\text { Dana (\%) }\end{array}$ & $\begin{array}{c}\text { Nilai } \\
\text { Kumulatif } \\
(\%)\end{array}$ & $\begin{array}{l}\mathrm{Ke} \\
\text { las }\end{array}$ \\
\hline 17 & Telor & 63640 & $\begin{array}{l}\mathrm{Rp} \\
22.500\end{array}$ & $\begin{array}{l}\mathrm{Rp} \\
1.431 .900 .000\end{array}$ & $\begin{array}{l}\mathrm{Rp} \\
1.431 .900 .000\end{array}$ & $29,60 \%$ & $29,60 \%$ & A \\
\hline 1 & Gula Pasir & 36035 & $\begin{array}{l}\mathrm{Rp} \\
12.500\end{array}$ & $\begin{array}{l}\mathrm{Rp} \\
450.437 .500\end{array}$ & $\begin{array}{l}\mathrm{Rp} \\
1.882 .337 .500\end{array}$ & $9,31 \%$ & $38,91 \%$ & A \\
\hline 27 & Award & 10605 & $\begin{array}{l}\mathrm{Rp} \\
19.213\end{array}$ & $\begin{array}{l}\mathrm{Rp} \\
203.753 .865\end{array}$ & $\begin{array}{l}\mathrm{Rp} \\
2.086 .091 .365\end{array}$ & $4,21 \%$ & $43,12 \%$ & A \\
\hline 18 & Keju Kraff & 2465 & $\begin{array}{l}\mathrm{Rp} \\
80.574\end{array}$ & $\begin{array}{l}\text { Rp } \\
198.614 .910\end{array}$ & $\begin{array}{l}\mathrm{Rp} \\
2.284 .706 .275\end{array}$ & $4,11 \%$ & $47,23 \%$ & A \\
\hline 8 & $\begin{array}{l}\text { Tepung Tali Mas } \\
\text { New }\end{array}$ & 26675 & $\begin{array}{l}\mathrm{Rp} \\
7.180\end{array}$ & $\begin{array}{l}\mathrm{Rp} \\
191.526 .500\end{array}$ & $\begin{array}{l}\mathrm{Rp} \\
2.476 .232 .775\end{array}$ & $3,96 \%$ & $51,19 \%$ & A \\
\hline 3 & Gula Aren & 8102 & $\begin{array}{l}\mathrm{Rp} \\
17.500\end{array}$ & $\begin{array}{l}\mathrm{Rp} \\
141.785 .000\end{array}$ & $\begin{array}{l}\mathrm{Rp} \\
2.618 .017 .775\end{array}$ & $2,93 \%$ & $54,12 \%$ & A \\
\hline 9 & Tepung Segitiga & 19100 & $\begin{array}{l}\mathrm{Rp} \\
7.020\end{array}$ & $\begin{array}{l}\mathrm{Rp} \\
134.082 .000\end{array}$ & $\begin{array}{l}\mathrm{Rp} \\
2.752 .099 .775\end{array}$ & $2,77 \%$ & $56,89 \%$ & A \\
\hline 19 & Keju MEG & 2113,2 & $\begin{array}{l}\mathrm{Rp} \\
60.000\end{array}$ & $\begin{array}{l}\mathrm{Rp} \\
126.792 .000\end{array}$ & $\begin{array}{l}\mathrm{Rp} \\
2.878 .891 .775\end{array}$ & $2,62 \%$ & $59,51 \%$ & A \\
\hline 2 & Gula Halus & 8645 & $\begin{array}{l}\mathrm{Rp} \\
14.500\end{array}$ & $\begin{array}{l}\mathrm{Rp} \\
125.352 .500\end{array}$ & $\begin{array}{l}\mathrm{Rp} \\
3.004 .244 .275\end{array}$ & $2,59 \%$ & $62,10 \%$ & A \\
\hline 63 & Almond & 840,92 & $\begin{array}{l}\mathrm{Rp} \\
143.81 \\
1\end{array}$ & $\begin{array}{l}\mathrm{Rp} \\
120.933 .546\end{array}$ & $\begin{array}{l}\mathrm{Rp} \\
3.125 .177 .821\end{array}$ & $2,50 \%$ & $64,60 \%$ & A \\
\hline 41 & $\begin{array}{l}\text { Tulip Dark } \\
\text { Compound }\end{array}$ & 2698,4 & $\begin{array}{l}\mathrm{Rp} \\
39.425\end{array}$ & $\begin{array}{l}\mathrm{Rp} \\
106.384 .420\end{array}$ & $\begin{array}{l}\mathrm{Rp} \\
3.231 .562 .241\end{array}$ & $2,20 \%$ & $66,80 \%$ & A \\
\hline 47 & $\begin{array}{l}\text { Filling Elmer } \\
\text { Cookies }\end{array}$ & 1570 & $\begin{array}{l}\mathrm{Rp} \\
63.800\end{array}$ & $\begin{array}{l}\mathrm{Rp} \\
100.166 .000\end{array}$ & $\begin{array}{l}\mathrm{Rp} \\
3.331 .728 .241\end{array}$ & $2,07 \%$ & $68,87 \%$ & A \\
\hline 44 & Coklat Bubuk & 745 & $\begin{array}{l}\mathrm{Rp} \\
121.82 \\
5\end{array}$ & $\begin{array}{l}\mathrm{Rp} \\
90.759 .625\end{array}$ & $\begin{array}{l}\mathrm{Rp} \\
3.422 .487 .866\end{array}$ & $1,88 \%$ & $70,75 \%$ & A \\
\hline 28 & S'perior & 3885 & $\begin{array}{l}\mathrm{Rp} \\
22.647\end{array}$ & $\begin{array}{l}\mathrm{Rp} \\
87.983 .595\end{array}$ & $\begin{array}{l}\mathrm{Rp} \\
3.510 .471 .461\end{array}$ & $1,82 \%$ & $72,56 \%$ & A \\
\hline 5 & Susu Bubuk & 1400 & $\begin{array}{l}\mathrm{Rp} \\
58.805\end{array}$ & $\begin{array}{l}\mathrm{Rp} \\
82.327 .000\end{array}$ & $\begin{array}{l}\mathrm{Rp} \\
3.592 .798 .461\end{array}$ & $1,70 \%$ & $74,27 \%$ & A \\
\hline 48 & $\begin{array}{l}\text { Filling Dunia } \\
\text { Elmer }\end{array}$ & 1825 & $\begin{array}{l}\mathrm{Rp} \\
36.530\end{array}$ & $\begin{array}{l}\mathrm{Rp} \\
66.667 .250\end{array}$ & $\begin{array}{l}\mathrm{Rp} \\
3.659 .465 .711\end{array}$ & $1,38 \%$ & $75,64 \%$ & A \\
\hline 42 & Elmer White & 1507,5 & $\begin{array}{l}\mathrm{Rp} \\
42.167\end{array}$ & $\begin{array}{l}\mathrm{Rp} \\
63.566 .753\end{array}$ & $\begin{array}{l}\mathrm{Rp} \\
3.723 .032 .464\end{array}$ & $1,31 \%$ & $76,96 \%$ & A \\
\hline 14 & $\begin{array}{l}\text { Tepung Chiffon } \\
\text { Vanilla }\end{array}$ & 1496 & $\begin{array}{l}\mathrm{Rp} \\
42.300 \\
\end{array}$ & $\begin{array}{l}\mathrm{Rp} \\
63.280 .800 \\
\end{array}$ & $\begin{array}{l}\mathrm{Rp} \\
3.786 .313 .264 \\
\end{array}$ & $1,31 \%$ & $78,27 \%$ & A \\
\hline 15 & Blondie Tiramisu & 1214 & $\begin{array}{l}\mathrm{Rp} \\
50.925\end{array}$ & $\begin{array}{l}\mathrm{Rp} \\
61.822 .950\end{array}$ & $\begin{array}{l}\mathrm{Rp} \\
3.848 .136 .214\end{array}$ & $1,28 \%$ & $79,54 \%$ & A \\
\hline 37 & Minyak Goreng & 355 & $\begin{array}{l}\mathrm{Rp} \\
170.00 \\
0\end{array}$ & $\begin{array}{l}\mathrm{Rp} \\
60.350 .000\end{array}$ & $\begin{array}{l}\text { Rp } \\
3.908 .486 .214\end{array}$ & $1,25 \%$ & $80,79 \%$ & B \\
\hline 46 & DF-400 & 460 & $\mathrm{Rp}$ & $\mathrm{Rp}$ & $\mathrm{Rp}$ & $1,07 \%$ & $81,86 \%$ & B \\
\hline
\end{tabular}

http://journals.usm.ac.id/index.php/solusi 
SOLUSI : Jurnal Ilmiah Bidang Ilmu Ekonomi Vol. 19, No. 1 , Januari 2021, Hal 60-75
Fakultas Ekonomi Universitas Semarang

P-ISSN : 1412-5331, E-ISSN : 2716-2532

\begin{tabular}{|c|c|c|c|c|c|c|c|c|}
\hline & & & $\begin{array}{l}112.50 \\
0\end{array}$ & 51.750 .000 & 3.960 .236 .214 & & & \\
\hline 45 & DF-300 & 460 & $\begin{array}{l}\mathrm{Rp} \\
105.00 \\
0\end{array}$ & $\begin{array}{l}\mathrm{Rp} \\
48.300 .000\end{array}$ & $\begin{array}{l}\mathrm{Rp} \\
4.008 .536 .214\end{array}$ & $1,00 \%$ & $82,86 \%$ & B \\
\hline 40 & SP-Hanwe & 1340 & $\begin{array}{l}\mathrm{Rp} \\
31.050\end{array}$ & $\begin{array}{l}\mathrm{Rp} \\
41.607 .000\end{array}$ & $\begin{array}{l}\mathrm{Rp} \\
4.050 .143 .214\end{array}$ & $0,86 \%$ & $83,72 \%$ & B \\
\hline 31 & Mother's Choice & 2715 & $\begin{array}{l}\mathrm{Rp} \\
15.260\end{array}$ & $\begin{array}{l}\mathrm{Rp} \\
41.430 .900\end{array}$ & $\begin{array}{l}\mathrm{Rp} \\
4.091 .574 .114\end{array}$ & $0,86 \%$ & $84,58 \%$ & $\mathrm{~B}$ \\
\hline 24 & Vanilla Paste & 298 & $\begin{array}{l}\mathrm{Rp} \\
134.16 \\
7\end{array}$ & $\begin{array}{l}\mathrm{Rp} \\
39.981 .766\end{array}$ & $\begin{array}{l}\mathrm{Rp} \\
4.131 .555 .880\end{array}$ & $0,83 \%$ & $85,40 \%$ & B \\
\hline 34 & RBS & 37 & $\begin{array}{l}\mathrm{Rp} \\
1.080 .0 \\
00\end{array}$ & $\begin{array}{l}\mathrm{Rp} \\
39.960 .000\end{array}$ & $\begin{array}{l}\mathrm{Rp} \\
4.171 .515 .880\end{array}$ & $0,83 \%$ & $86,23 \%$ & B \\
\hline 13 & CPT Stabil & 714 & $\begin{array}{l}\mathrm{Rp} \\
53.350\end{array}$ & $\begin{array}{l}\mathrm{Rp} \\
38.091 .900\end{array}$ & $\begin{array}{l}\mathrm{Rp} \\
4.209 .607 .780\end{array}$ & $0,79 \%$ & $87,02 \%$ & B \\
\hline 23 & Black Forest & 261 & $\begin{array}{l}\text { Rp } \\
144.16 \\
7\end{array}$ & $\begin{array}{l}\mathrm{Rp} \\
37.627 .587\end{array}$ & $\begin{array}{l}\mathrm{Rp} \\
4.247 .235 .367\end{array}$ & $0,78 \%$ & $87,79 \%$ & B \\
\hline 6 & Susu Cair & 2733 & $\begin{array}{l}\mathrm{Rp} \\
12.341\end{array}$ & $\begin{array}{l}\mathrm{Rp} \\
33.727 .953\end{array}$ & $\begin{array}{l}\mathrm{Rp} \\
4.280 .963 .320\end{array}$ & $0,70 \%$ & $88,49 \%$ & B \\
\hline 10 & Tepung Pati & 3998 & $\begin{array}{l}\mathrm{Rp} \\
8.300\end{array}$ & $\begin{array}{l}\mathrm{Rp} \\
33.183 .400\end{array}$ & $\begin{array}{l}\mathrm{Rp} \\
4.314 .146 .720\end{array}$ & $0,69 \%$ & $89,18 \%$ & $\mathrm{~B}$ \\
\hline 55 & Selai Strowbery & 890 & $\begin{array}{l}\mathrm{Rp} \\
36.750\end{array}$ & $\begin{array}{l}\mathrm{Rp} \\
32.707 .500\end{array}$ & $\begin{array}{l}\mathrm{Rp} \\
4.346 .854 .220\end{array}$ & $0,68 \%$ & $89,85 \%$ & B \\
\hline 43 & Collata Dark & 653 & $\begin{array}{l}\mathrm{Rp} \\
46.305\end{array}$ & $\begin{array}{l}\mathrm{Rp} \\
30.237 .165\end{array}$ & $\begin{array}{l}\mathrm{Rp} \\
4.377 .091 .385\end{array}$ & $0,63 \%$ & $90,48 \%$ & B \\
\hline 20 & Keju Tua & 162,68 & $\begin{array}{l}\mathrm{Rp} \\
185.00 \\
0\end{array}$ & $\begin{array}{l}\mathrm{Rp} \\
30.095 .800\end{array}$ & $\begin{array}{l}\mathrm{Rp} \\
4.407 .187 .185\end{array}$ & $0,62 \%$ & $91,10 \%$ & B \\
\hline 70 & Olex & 95 & \begin{tabular}{l}
\multicolumn{1}{c}{$\mathrm{Rp}$} \\
255.00 \\
0
\end{tabular} & $\begin{array}{l}\mathrm{Rp} \\
24.225 .000\end{array}$ & $\begin{array}{l}\mathrm{Rp} \\
4.431 .412 .185\end{array}$ & $0,50 \%$ & $91,60 \%$ & B \\
\hline 64 & Ragi & 531,5 & $\begin{array}{l}\mathrm{Rp} \\
45.000\end{array}$ & $\begin{array}{l}\mathrm{Rp} \\
23.917 .500\end{array}$ & $\begin{array}{l}\mathrm{Rp} \\
4.455 .329 .685\end{array}$ & $0,49 \%$ & $92,10 \%$ & B \\
\hline 93 & $\begin{array}{l}\text { Tepung Ketan } \\
\text { Hitam }\end{array}$ & 670 & $\begin{array}{l}\mathrm{Rp} \\
35.000\end{array}$ & $\begin{array}{l}\mathrm{Rp} \\
23.450 .000\end{array}$ & $\begin{array}{l}\mathrm{Rp} \\
4.478 .779 .685\end{array}$ & $0,48 \%$ & $92,58 \%$ & B \\
\hline 11 & Maizena & 1625 & $\begin{array}{l}\mathrm{Rp} \\
13.225\end{array}$ & $\begin{array}{l}\mathrm{Rp} \\
21.490 .625\end{array}$ & $\begin{array}{l}\mathrm{Rp} \\
4.500 .270 .310\end{array}$ & $0,44 \%$ & $93,02 \%$ & B \\
\hline 78 & $\begin{array}{l}\text { Bumbu Lapis } \\
\text { Legit }\end{array}$ & 221 & $\begin{array}{l}\mathrm{Rp} \\
93.500\end{array}$ & $\begin{array}{l}\mathrm{Rp} \\
20.663 .500\end{array}$ & $\begin{array}{l}\mathrm{Rp} \\
4.520 .933 .810\end{array}$ & $0,43 \%$ & $93,45 \%$ & B \\
\hline 57 & Selai Nanas & 365 & $\begin{array}{l}\mathrm{Rp} \\
53.350\end{array}$ & $\begin{array}{l}\mathrm{Rp} \\
19.472 .750\end{array}$ & $\begin{array}{l}\mathrm{Rp} \\
4.540 .406 .560\end{array}$ & $0,40 \%$ & $93,85 \%$ & B \\
\hline 49 & Chocochip Tulip & 470 & $\begin{array}{l}\mathrm{Rp} \\
41.292\end{array}$ & $\begin{array}{l}\mathrm{Rp} \\
19.407 .240\end{array}$ & $\begin{array}{l}\mathrm{Rp} \\
4.559 .813 .800\end{array}$ & $0,40 \%$ & $94,25 \%$ & B \\
\hline 67 & Wijen & 388 & $\begin{array}{l}\mathrm{Rp} \\
44.000\end{array}$ & $\begin{array}{l}\mathrm{Rp} \\
17.072 .000\end{array}$ & $\begin{array}{l}\mathrm{Rp} \\
4.576 .885 .800\end{array}$ & $0,35 \%$ & $94,61 \%$ & B \\
\hline 35 & Butter Anchor & 137,9 & $\begin{array}{l}\mathrm{Rp} \\
108.94 \\
5\end{array}$ & $\begin{array}{l}\mathrm{Rp} \\
15.023 .516\end{array}$ & $\begin{array}{l}\mathrm{Rp} \\
4.591 .909 .315\end{array}$ & $0,31 \%$ & $94,92 \%$ & B \\
\hline 50 & Meses & 515,5 & $\begin{array}{l}\mathrm{Rp} \\
26.400\end{array}$ & $\begin{array}{l}\mathrm{Rp} \\
13.609 .200\end{array}$ & $\begin{array}{l}\mathrm{Rp} \\
4.605 .518 .515\end{array}$ & $0,28 \%$ & $95,20 \%$ & B \\
\hline 16 & Custart & 210 & $\begin{array}{l}\mathrm{Rp} \\
63.900\end{array}$ & $\begin{array}{l}\mathrm{Rp} \\
13.419 .000\end{array}$ & $\begin{array}{l}\mathrm{Rp} \\
4.618 .937 .515\end{array}$ & $0,28 \%$ & $95,48 \%$ & B \\
\hline 84 & Paping Bag & 599 & $\begin{array}{l}\mathrm{Rp} \\
18.500\end{array}$ & $\begin{array}{l}\mathrm{Rp} \\
11.081 .500\end{array}$ & $\begin{array}{l}\mathrm{Rp} \\
4.630 .019 .015\end{array}$ & $0,23 \%$ & $95,71 \%$ & $\mathrm{C}$ \\
\hline 12 & $\begin{array}{l}\text { Tepung Pita } \\
\text { Merah }\end{array}$ & 1330 & $\begin{array}{l}\mathrm{Rp} \\
7.350\end{array}$ & $\begin{array}{l}\mathrm{Rp} \\
9.775 .500\end{array}$ & $\begin{array}{l}\mathrm{Rp} \\
4.639 .794 .515\end{array}$ & $0,20 \%$ & $95,91 \%$ & $\mathrm{C}$ \\
\hline 52 & Cheese Powder & 63 & $\begin{array}{l}\mathrm{Rp} \\
150.00 \\
0\end{array}$ & $\begin{array}{l}\mathrm{Rp} \\
9.450 .000\end{array}$ & $\begin{array}{l}\mathrm{Rp} \\
4.649 .244 .515\end{array}$ & $0,20 \%$ & $96,10 \%$ & $\mathrm{C}$ \\
\hline 92 & Maglame & 63 & $\mathrm{Rp}$ & $\mathrm{Rp}$ & $\mathrm{Rp}$ & $0,18 \%$ & $96,28 \%$ & $\mathrm{C}$ \\
\hline
\end{tabular}

http://journals.usm.ac.id/index.php/solusi 
SOLUSI : Jurnal Ilmiah Bidang Ilmu Ekonomi Vol. 19, No. 1 , Januari 2021, Hal 60-75
Fakultas Ekonomi Universitas Semarang

P-ISSN : 1412-5331, E-ISSN : 2716-2532

\begin{tabular}{|c|c|c|c|c|c|c|c|c|}
\hline & & & $\begin{array}{l}138.00 \\
0\end{array}$ & 8.694 .000 & 4.657.938.515 & & & \\
\hline 56 & Selai Mangga & 245 & $\begin{array}{l}\mathrm{Rp} \\
34.870\end{array}$ & $\begin{array}{l}\mathrm{Rp} \\
8.543 .150\end{array}$ & $\begin{array}{l}\mathrm{Rp} \\
4.666 .481 .665\end{array}$ & $0,18 \%$ & $96,46 \%$ & $\mathrm{C}$ \\
\hline 58 & Cheese Paste & 20 & $\begin{array}{l}\mathrm{Rp} \\
425.00 \\
0\end{array}$ & $\begin{array}{l}\mathrm{Rp} \\
8.500 .000\end{array}$ & $\begin{array}{l}\mathrm{Rp} \\
4.674 .981 .665\end{array}$ & $0,18 \%$ & $96,64 \%$ & $\mathrm{C}$ \\
\hline 51 & Tulip Noir & 62,5 & $\begin{array}{l}\mathrm{Rp} \\
131.88 \\
1\end{array}$ & $\begin{array}{l}\mathrm{Rp} \\
8.242 .563\end{array}$ & $\begin{array}{l}\mathrm{Rp} \\
4.683 .224 .228\end{array}$ & $0,17 \%$ & $96,81 \%$ & $\mathrm{C}$ \\
\hline 62 & Flavour Pandan & 28 & $\begin{array}{l}\text { Rp } \\
284.50 \\
0\end{array}$ & $\begin{array}{l}\mathrm{Rp} \\
7.966 .000\end{array}$ & $\begin{array}{l}\mathrm{Rp} \\
4.691 .190 .228\end{array}$ & $0,16 \%$ & $96,97 \%$ & $\mathrm{C}$ \\
\hline 29 & Bread-O & 390 & $\begin{array}{l}\mathrm{Rp} \\
20.413\end{array}$ & $\begin{array}{l}\mathrm{Rp} \\
7.961 .070\end{array}$ & $\begin{array}{l}\mathrm{Rp} \\
4.699 .151 .298\end{array}$ & $0,16 \%$ & $97,14 \%$ & $\mathrm{C}$ \\
\hline 82 & Cup Diva 11 Putih & 170 & $\begin{array}{l}\mathrm{Rp} \\
40.625\end{array}$ & $\begin{array}{l}\mathrm{Rp} \\
6.906 .250\end{array}$ & $\begin{array}{l}\mathrm{Rp} \\
4.706 .057 .548\end{array}$ & $0,14 \%$ & $97,28 \%$ & $\mathrm{C}$ \\
\hline 53 & Selai Pandan & 212 & $\begin{array}{l}\mathrm{Rp} \\
31.000\end{array}$ & $\begin{array}{l}\mathrm{Rp} \\
6.572 .000\end{array}$ & $\begin{array}{l}\mathrm{Rp} \\
4.712 .629 .548\end{array}$ & $0,14 \%$ & $97,41 \%$ & $\mathrm{C}$ \\
\hline 30 & Medal & 255 & $\begin{array}{l}\mathrm{Rp} \\
25.707\end{array}$ & $\begin{array}{l}\mathrm{Rp} \\
6.555 .285\end{array}$ & $\begin{array}{l}\mathrm{Rp} \\
4.719 .184 .833\end{array}$ & $0,14 \%$ & $97,55 \%$ & $\mathrm{C}$ \\
\hline 39 & Quick-75 & 140 & $\begin{array}{l}\mathrm{Rp} \\
46.200\end{array}$ & $\begin{array}{l}\mathrm{Rp} \\
6.468 .000\end{array}$ & $\begin{array}{l}\mathrm{Rp} \\
4.725 .652 .833\end{array}$ & $0,13 \%$ & $97,68 \%$ & $\mathrm{C}$ \\
\hline 32 & BOS & 300 & $\begin{array}{l}\mathrm{Rp} \\
21.420\end{array}$ & $\begin{array}{l}\mathrm{Rp} \\
6.426 .000\end{array}$ & $\begin{array}{l}\mathrm{Rp} \\
4.732 .078 .833\end{array}$ & $0,13 \%$ & $97,82 \%$ & $\mathrm{C}$ \\
\hline 36 & Unsalted Butter & 73,8 & $\begin{array}{l}\mathrm{Rp} \\
86.625\end{array}$ & $\begin{array}{l}\mathrm{Rp} \\
6.392 .925\end{array}$ & $\begin{array}{l}\mathrm{Rp} \\
4.738 .471 .758\end{array}$ & $0,13 \%$ & $97,95 \%$ & $\mathrm{C}$ \\
\hline 4 & Dextrose & 650 & $\begin{array}{l}\text { Rp } \\
9.800 \\
\end{array}$ & $\begin{array}{l}\mathrm{Rp} \\
6.370 .000\end{array}$ & $\begin{array}{l}\mathrm{Rp} \\
4.744 .841 .758 \\
\end{array}$ & $0,13 \%$ & $98,08 \%$ & $\mathrm{C}$ \\
\hline 54 & Selai Bluebery & 170 & $\begin{array}{l}\mathrm{Rp} \\
36.750\end{array}$ & $\begin{array}{l}\mathrm{Rp} \\
6.247 .500\end{array}$ & $\begin{array}{l}\mathrm{Rp} \\
4.751 .089 .258\end{array}$ & $0,13 \%$ & $98,21 \%$ & $\mathrm{C}$ \\
\hline 74 & Baking Powder & 200 & $\begin{array}{l}\mathrm{Rp} \\
29.900\end{array}$ & $\begin{array}{l}\mathrm{Rp} \\
5.980 .000\end{array}$ & $\begin{array}{l}\mathrm{Rp} \\
4.757 .069 .258\end{array}$ & $0,12 \%$ & $98,33 \%$ & $\mathrm{C}$ \\
\hline 38 & Frescoplus & 88 & $\begin{array}{l}\mathrm{Rp} \\
63.500\end{array}$ & $\begin{array}{l}\mathrm{Rp} \\
5.588 .000\end{array}$ & $\begin{array}{l}\mathrm{Rp} \\
4.762 .657 .258\end{array}$ & $0,12 \%$ & $98,45 \%$ & $\mathrm{C}$ \\
\hline 33 & Palmia & 570 & $\begin{array}{l}\text { Rp } \\
9.350\end{array}$ & $\begin{array}{l}\mathrm{Rp} \\
5.329 .500\end{array}$ & $\begin{array}{l}\mathrm{Rp} \\
4.767 .986 .758\end{array}$ & $0,11 \%$ & $98,56 \%$ & $\mathrm{C}$ \\
\hline 83 & Cup Diva Gold & 35 & $\begin{array}{l}\mathrm{Rp} \\
131.25 \\
0\end{array}$ & $\begin{array}{l}\mathrm{Rp} \\
4.593 .750\end{array}$ & $\begin{array}{l}\mathrm{Rp} \\
4.772 .580 .508\end{array}$ & $0,09 \%$ & $98,65 \%$ & $\mathrm{C}$ \\
\hline 60 & Coconat Paste & 17 & $\begin{array}{l}\mathrm{Rp} \\
265.00 \\
0\end{array}$ & $\begin{array}{l}\mathrm{Rp} \\
4.505 .000\end{array}$ & $\begin{array}{l}\mathrm{Rp} \\
4.777 .085 .508\end{array}$ & $0,09 \%$ & $98,75 \%$ & $\mathrm{C}$ \\
\hline 68 & Nescafe & 296 & $\begin{array}{l}\mathrm{Rp} \\
14.750\end{array}$ & $\begin{array}{l}\mathrm{Rp} \\
4.366 .000\end{array}$ & $\begin{array}{l}\mathrm{Rp} \\
4.781 .451 .508\end{array}$ & $0,09 \%$ & $98,84 \%$ & $\mathrm{C}$ \\
\hline 21 & Fanta & 1052 & $\begin{array}{l}\mathrm{Rp} \\
3.833\end{array}$ & $\begin{array}{l}\mathrm{Rp} \\
4.032 .316\end{array}$ & $\begin{array}{l}\mathrm{Rp} \\
4.785 .483 .824\end{array}$ & $0,08 \%$ & $98,92 \%$ & $\mathrm{C}$ \\
\hline 75 & Cream Of Tart & 70 & $\begin{array}{l}\mathrm{Rp} \\
56.925\end{array}$ & $\begin{array}{l}\mathrm{Rp} \\
3.984 .750\end{array}$ & $\begin{array}{l}\mathrm{Rp} \\
4.789 .468 .574\end{array}$ & $0,08 \%$ & $99,00 \%$ & $\mathrm{C}$ \\
\hline 86 & Alkohol & 361 & $\begin{array}{l}\mathrm{Rp} \\
11.000\end{array}$ & $\begin{array}{l}\mathrm{Rp} \\
3.971 .000\end{array}$ & $\begin{array}{l}\mathrm{Rp} \\
4.793 .439 .574\end{array}$ & $0,08 \%$ & $99,08 \%$ & $\mathrm{C}$ \\
\hline 65 & Agar-Agar & 1238 & $\begin{array}{l}\mathrm{Rp} \\
3.000\end{array}$ & $\begin{array}{l}\mathrm{Rp} \\
3.714 .000\end{array}$ & $\begin{array}{l}\mathrm{Rp} \\
4.797 .153 .574\end{array}$ & $0,08 \%$ & $99,16 \%$ & $\mathrm{C}$ \\
\hline 22 & Sprite & 878 & $\begin{array}{l}\mathrm{Rp} \\
3.833 \\
\end{array}$ & $\begin{array}{l}\mathrm{Rp} \\
3.365 .374\end{array}$ & $\begin{array}{l}\mathrm{Rp} \\
4.800 .518 .948\end{array}$ & $0,07 \%$ & $99,23 \%$ & $\mathrm{C}$ \\
\hline 95 & Kismis & 41 & $\begin{array}{l}\mathrm{Rp} \\
81.000\end{array}$ & $\begin{array}{l}\mathrm{Rp} \\
3.321 .000\end{array}$ & $\begin{array}{l}\mathrm{Rp} \\
4.803 .839 .948\end{array}$ & $0,07 \%$ & $99,30 \%$ & $\mathrm{C}$ \\
\hline 85 & $\begin{array}{l}\text { Kertas Anti } \\
\text { Lengket }\end{array}$ & 13 & \begin{tabular}{l}
\multicolumn{1}{c}{ Rp } \\
255.00 \\
0
\end{tabular} & $\begin{array}{l}\mathrm{Rp} \\
3.315 .000\end{array}$ & $\begin{array}{l}\mathrm{Rp} \\
4.807 .154 .948\end{array}$ & $0,07 \%$ & $99,37 \%$ & $\mathrm{C}$ \\
\hline 71 & Super Soft & 43,8 & $\begin{array}{l}\mathrm{Rp} \\
73.800\end{array}$ & $\begin{array}{l}\mathrm{Rp} \\
3.232 .440\end{array}$ & $\begin{array}{l}\mathrm{Rp} \\
4.810 .387 .388\end{array}$ & $0,07 \%$ & $99,43 \%$ & $\mathrm{C}$ \\
\hline 61 & Paste Pandan & 20 & $\mathrm{Rp}$ & $\mathrm{Rp}$ & $\mathrm{Rp}$ & $0,07 \%$ & $99,50 \%$ & C \\
\hline
\end{tabular}

http://journals.usm.ac.id/index.php/solusi 


\begin{tabular}{|c|c|c|c|c|c|c|c|c|}
\hline & & & $\begin{array}{l}163.50 \\
0\end{array}$ & 3.270 .000 & 4.813.657.388 & & & \\
\hline 79 & Anise & 17 & $\begin{array}{l}\mathrm{Rp} \\
176.00 \\
0\end{array}$ & $\begin{array}{l}\mathrm{Rp} \\
2.992 .000\end{array}$ & $\begin{array}{l}\mathrm{Rp} \\
4.816 .649 .388\end{array}$ & $0,06 \%$ & $99,56 \%$ & $\mathrm{C}$ \\
\hline 81 & Creamivite & 35,5 & $\begin{array}{l}\mathrm{Rp} \\
74.360\end{array}$ & $\begin{array}{l}\mathrm{Rp} \\
2.639 .780\end{array}$ & $\begin{array}{l}\mathrm{Rp} \\
4.819 .289 .168\end{array}$ & $0,05 \%$ & $99,62 \%$ & $\mathrm{C}$ \\
\hline 69 & Vanilla Cream & 25 & $\begin{array}{l}\text { Rp } \\
103.33 \\
3\end{array}$ & $\begin{array}{l}\mathrm{Rp} \\
2.583 .325\end{array}$ & $\begin{array}{l}\mathrm{Rp} \\
4.821 .872 .493\end{array}$ & $0,05 \%$ & $99,67 \%$ & $\mathrm{C}$ \\
\hline 59 & Bluebery Paste & 16 & $\begin{array}{l}\mathrm{Rp} \\
155.00 \\
0\end{array}$ & $\begin{array}{l}\mathrm{Rp} \\
2.480 .000\end{array}$ & $\begin{array}{l}\mathrm{Rp} \\
4.824 .352 .493\end{array}$ & $0,05 \%$ & $99,72 \%$ & $\mathrm{C}$ \\
\hline 7 & $\begin{array}{l}\text { Susu Kental } \\
\text { Manis }\end{array}$ & 248 & $\begin{array}{l}\mathrm{Rp} \\
9.083\end{array}$ & $\begin{array}{l}\mathrm{Rp} \\
2.252 .584\end{array}$ & $\begin{array}{l}\mathrm{Rp} \\
4.826 .605 .077\end{array}$ & $0,05 \%$ & $99,77 \%$ & $\mathrm{C}$ \\
\hline 26 & Perisa Melon & 23 & $\begin{array}{l}\mathrm{Rp} \\
82.225\end{array}$ & $\begin{array}{l}\mathrm{Rp} \\
1.891 .175\end{array}$ & $\begin{array}{l}\mathrm{Rp} \\
4.828 .496 .252\end{array}$ & $0,04 \%$ & $99,81 \%$ & $\mathrm{C}$ \\
\hline 73 & Potasium & 22,9 & $\begin{array}{l}\mathrm{Rp} \\
72.000\end{array}$ & $\begin{array}{l}\mathrm{Rp} \\
1.648 .800\end{array}$ & $\begin{array}{l}\mathrm{Rp} \\
4.830 .145 .052\end{array}$ & $0,03 \%$ & $99,84 \%$ & $\mathrm{C}$ \\
\hline 72 & Calsium & 24,4 & $\begin{array}{l}\mathrm{Rp} \\
63.000\end{array}$ & $\begin{array}{l}\mathrm{Rp} \\
1.537 .200\end{array}$ & $\begin{array}{l}\mathrm{Rp} \\
4.831 .682 .252\end{array}$ & $0,03 \%$ & $99,87 \%$ & $\mathrm{C}$ \\
\hline 25 & Strowbwry Paste & 10 & $\begin{array}{l}\mathrm{Rp} \\
120.00 \\
0\end{array}$ & $\begin{array}{l}\mathrm{Rp} \\
1.200 .000\end{array}$ & $\begin{array}{l}\mathrm{Rp} \\
4.832 .882 .252\end{array}$ & $0,02 \%$ & $99,90 \%$ & $\mathrm{C}$ \\
\hline 80 & GMS & 26 & $\begin{array}{l}\mathrm{Rp} \\
45.000\end{array}$ & $\begin{array}{l}\mathrm{Rp} \\
1.170 .000\end{array}$ & $\begin{array}{l}\mathrm{Rp} \\
4.834 .052 .252\end{array}$ & $0,02 \%$ & $99,92 \%$ & $\mathrm{C}$ \\
\hline 77 & Gelatin & 7 & $\begin{array}{l}\mathrm{Rp} \\
157.20 \\
0\end{array}$ & $\begin{array}{l}\mathrm{Rp} \\
1.100 .400\end{array}$ & $\begin{array}{l}\mathrm{Rp} \\
4.835 .152 .652\end{array}$ & $0,02 \%$ & $99,95 \%$ & $\mathrm{C}$ \\
\hline 66 & Meggi Ayam & 30 & $\begin{array}{l}\mathrm{Rp} \\
33.350\end{array}$ & $\begin{array}{l}\mathrm{Rp} \\
1.000 .500\end{array}$ & $\begin{array}{l}\mathrm{Rp} \\
4.836 .153 .152\end{array}$ & $0,02 \%$ & $99,97 \%$ & $\mathrm{C}$ \\
\hline 76 & Soda Kue & 50 & $\begin{array}{l}\mathrm{Rp} \\
12.650\end{array}$ & $\begin{array}{l}\mathrm{Rp} \\
632.500\end{array}$ & $\begin{array}{l}\mathrm{Rp} \\
4.836 .785 .652\end{array}$ & $0,01 \%$ & $99,98 \%$ & $\mathrm{C}$ \\
\hline 94 & $\begin{array}{l}\text { Pewarna Kuning } \\
\text { Muda }\end{array}$ & 8 & $\begin{array}{l}\mathrm{Rp} \\
43.600\end{array}$ & $\begin{array}{l}\mathrm{Rp} \\
348.800\end{array}$ & $\begin{array}{l}\mathrm{Rp} \\
4.837 .134 .452\end{array}$ & $0,01 \%$ & $99,99 \%$ & $\mathrm{C}$ \\
\hline 88 & $\begin{array}{l}\text { Pewarna Kuning } \\
\text { Telor }\end{array}$ & 6 & $\begin{array}{l}\mathrm{Rp} \\
43.600\end{array}$ & $\begin{array}{l}\mathrm{Rp} \\
261.600\end{array}$ & $\begin{array}{l}\mathrm{Rp} \\
4.837 .396 .052\end{array}$ & $0,01 \%$ & $99,99 \%$ & $\mathrm{C}$ \\
\hline 91 & Perwarna Orange & 3 & $\begin{array}{l}\mathrm{Rp} \\
57.500\end{array}$ & $\begin{array}{l}\mathrm{Rp} \\
172.500\end{array}$ & $\begin{array}{l}\mathrm{Rp} \\
4.837 .568 .552\end{array}$ & $0,00 \%$ & $100,00 \%$ & $\mathrm{C}$ \\
\hline 87 & $\begin{array}{l}\text { Pewarna Merah } \\
\text { Cabe }\end{array}$ & 1 & $\begin{array}{l}\mathrm{Rp} \\
50.140\end{array}$ & $\begin{array}{l}\mathrm{Rp} \\
50.140\end{array}$ & $\begin{array}{l}\mathrm{Rp} \\
4.837 .618 .692\end{array}$ & $0,00 \%$ & $100,00 \%$ & $\mathrm{C}$ \\
\hline 89 & Pewarna Hijau & 2 & $\begin{array}{l}\mathrm{Rp} \\
43.600\end{array}$ & $\begin{array}{l}\mathrm{Rp} \\
87.200\end{array}$ & $\begin{array}{l}\mathrm{Rp} \\
4.837 .705 .892\end{array}$ & $0,00 \%$ & $100,00 \%$ & $\mathrm{C}$ \\
\hline 90 & Pewarna Ungu & 1 & $\begin{array}{l}\mathrm{Rp} \\
43.600\end{array}$ & $\begin{array}{l}\mathrm{Rp} \\
43.600\end{array}$ & $\begin{array}{l}\mathrm{Rp} \\
4.837 .749 .492\end{array}$ & $0,00 \%$ & $100,00 \%$ & $\mathrm{C}$ \\
\hline & Jumlah Penyerapan & una Ite & & $\begin{array}{l}\mathrm{Rp} \\
4.837 .749 .492\end{array}$ & & & & \\
\hline
\end{tabular}

Sumber data : Data sekunder yang telah diolah,2020

\section{Analisis klasifikasi ABC pada bahan baku di PT. Dyriana}

Setalah melakukan pengolahan data berdasarkan metode analisis ABC, dapat diperoleh kategori bahan baku sebagai berikut :

1. Kategori A : Telor, Gula pasir, Mentega Award, Keju kraff, Tepung Tali mas new, Gula aren. Tepung segitiga, Kegu MEG, Gula halus, Kacang Almond, Tulip dark compound, Filling elmer cookies, Coklat bubuk, Mentega S'perior, Susu bubuk, Filling dunia elmer, Elmer white, Tepung chiffon vanilla, dan Blondie tiramiu. 
2. Kategori B : Minyak Goreng, Coklat DF-400, Coklat DF-300, Sp-Hanwe, Mentega mother's choice, Vanilla paste, RBS, CPT Stabil, Black Forest, Susu cair, Tepung pati, Selai stowbery, Collata dark, Keju tua, Olex, Ragi, Tepung ketan hitam, Maizena, Bumbu lapis legit, Selai nanas, Chocochip tulip, Wijen, Butter anchor, Meses, dan Custart,.

3. Kategori C : Paping bag, Tepung pita merah Cheese powder, Maglame, Selai mangga, Cheese paste, Tulip noir, Flavour pandan, Mentega Bread-O, Cup diva 11 putih, Selai pandan, Mentega Medal, Quick-75, Mentega BOS, Unsalted batter, Dextrose, Selai Bluebery, Baking powder, Frescoplus, Mentega palmia, Cup diva gold, Coconat paste, Nescafe, Fanta, Cream of tart, Alkohol, Agar-agar, Sprite,Kismis, Kertas anti lengket, Super soft, Paste pandan, Anise, Creamivite, Vanilla Cream, Bluebery paste, Susu kental manis, Perisa melon, Potasium, Calsium, Strowbery paste, GMS, Gelatin, Maggi ayam, Soda kue, Pewarna kuning muda, Pewarna kuning telor, Pewarna orange, Pewarna merah cabe, Pewarna hijau, dan Pewarna Ungu.

\section{Pembahasan}

Berdasarkan penelitian yang dilakukan di PT. Dyriana untuk penanganan pengendalian persediaan bahan baku untuk saat ini masih kurang efisien karena persediaan yang ada terkadang tidak terkontrol. Jika dilihat secara keseluruhan, jenis barang di gudang bahan baku terdiri dari 95 item. Melihat banyaknya komponen-komponen tersebut serta kondisi yang demikian tentu memerlukan penanganan khusus agar biaya yang dikeluarkan untuk persediaan lebih efisien, maka pada penelitian ini memerlukan kategorisasi komponenkomponen tersebut dengan menggunakan metode analisis ABC berdasarkan pada biaya-biaya yang dikeluarkaan dalam melakukan pembelian.

Berdasarkan teori menurut Bahagia (2006) dalam penelitian (Suhara 2017) pada prinsipnya analisis $\mathrm{ABC}$ adalah mengklasifikasian jenis barang yang didasarkan atas tingkat investasi tahunan yang terserap di dalam penyediaan persediaan untuk setiap jenis barang.

Pengelompokan bisa dilakukan untuk menentukan komponen-komponen apa saja yang membutuhkan pengendalian yang paling penting serta yang lebih dalam untuk perusahaan. Dengan ini penerapan metode $\mathrm{ABC}$ diharapkan dapat membantu perusahaan dalam memilih serta mengklasifikasi jenis komponen barang yang mana lebih utama dari pada komponen barang yang lainnya.

Berdasarkan analisis $\mathrm{ABC}$ yang diterapkan ada 3 kategori sebagai berikut :

Tabel 4.5

Pengelompokan Barang Dengan Analisis ABC Berdasarkan Jumlah Barang dan Biaya

\begin{tabular}{|c|c|c|cc|r|r|}
\hline No & Kategori & $\begin{array}{c}\text { Jumlah } \\
\text { item }\end{array}$ & Biaya (Rp) & $\begin{array}{c}\text { Presentasi } \\
\text { item (\%) }\end{array}$ & $\begin{array}{r}\text { Presentasi } \\
\text { biaya (\%) }\end{array}$ \\
\hline 1 & A & 19 & Rp & 3.848 .136 .214 & 20 & 80 \\
\hline
\end{tabular}




\begin{tabular}{|r|r|r|rr|r|r|}
2 & $\mathrm{~B}$ & 25 & $\mathrm{Rp}$ & 770.801 .302 & 26 & 15 \\
\hline 3 & $\mathrm{C}$ & 51 & $\mathrm{Rp}$ & 218.811 .977 & 54 & 5 \\
\hline & & 95 & $\mathrm{Rp}$ & 4.837 .749 .492 & 100 & 100 \\
\hline
\end{tabular}

Sumber data : Data Sekunder yang telah diolah, 2020

Berdasarkan analisis $\mathrm{ABC}$ tersebut terlihat bahwa jumlah barang yang termasuk dalam kategori A sebanyak 19 item atau sama dengan 20 persen dari jumlah seluruh item dengan biaya sebesar Rp 3.848.136.214 atau sama dengan 80 persen dari penyerapan seluruh dana persediaan, sedangkan yang termasuk kategori B sebanyak 25 item atau sama dengan 26 persen dari jumlah seluruh barang dengan biaya penyerapan sebesar Rp 770.801.302 atau sama dengan 15 persen, dan untuk kategori C sebanyak 51 item atau sama dengan 54 persen dari jumlah barang dengan biaya penyerapan sebesar Rp 218.811.977 atau sama dengan 5 persen.

Komponen-komponen yang termasuk kategori A membutuhkan pengendalian persediaan yang lebih tinggi jika dibandingkan dengan kategori B dan C. Agar tidak menimbulkan beban biaya yang besar dan mengakibatkan dana menganggur yang besar serta meningkatkan biaya penyimpanan pada kategori A, yang merupakan kategori yang paling penting dalam proses produksi ini, maka pengendalian persediaan perlu diperhatikan dengan lebih baik.

Perusahaan Dyriana bakery diharapkan dapat menerapkan analisis ABC didalam perencanaan persediaan bahan baku. Karena dalam analisis ABC ini perusahaan bisa membedakan mana barang yang memiliki prioritas yang lebih khusus dan memerlukan pengendalian yang kebih baik. Sehingga dapat menghemat biaya persediaan yang dikeluarkan untuk perusahaan tersebut.

\section{PENUTUP}

\section{Kesimpulan}

Berdasarkan analisis data dan pembahasan yang telah dilakukan maka dapat disimpulkan sebagai berikut :

1. Dengan menggunakan analisis $\mathrm{ABC}$ dapat dikelompokkan barang menurut nilai pemakaian dan nilai investasi dana persediaannya, sehingga lebih memudahkan di dalam perencanaan dan pengendalian persediaannya.

2. Dari analisis ABC yang diterapkan maka dapat dikategorikan

a. Kategori A memiliki peyerapan dana sebesar Rp 3.848.136.214 atau sama dengan 80 persen dari penyerapan seluruh dana persediaan,yang terdiri dari 19 item atau sama dengan 20 persen dari jumlah seluruh item.

b. Kategori B memiliki penyerapan dana sebesar Rp 770.801 .302 atau sama dengan 15 persen dari total penyerapan dana, yang terdiri dari sebanyak 26 item atau sama dengan 26 persen dari jumlah seluruh barang. 
c. Kategori C memiliki penyerapan dana sebesar Rp 218.811.977 atau sama dengan 5 persen, yang terdiri dari 51 item atau sama dengan 54 persen dari jumlah barang yang ada.

\section{Saran}

Setelah menganalisis masalah yang ada di perusahaan tersebut, maka penulis dapat mengajukan saran yang dapat menjadikan bahan pertimbangan dalam kebijakan pengelompokan bahan baku yang ada di perusahaan, adapun saranya sebagai berikut :

1. Hendaknya perusahaan mempertimbangkan penggunaan analisis $\mathrm{ABC}$ dalam kebijakan pengklasifikasian kategori barang yaitu dalam menggunakan analisis ABC, akan lebih mudah jika dalam peruahaan menetapkan kebijakan dan pengendalian untuk setiap kategori yang ada. Kebijakan yang dapat didasarkan pada analisis ABC mencakup halhal berikut :

a. Perkembangan sumber daya pembelian harus lebih tinggi yang dibayar kepada pemasok untuk persediaan kategori A dibantingkan persediaan kategori B dan C.

b. Persediaan kategori A, berbeda dengan persediaan kategori B dan kategori $\mathrm{C}$, harus dikendalikan secara lebih khusus. Mungkin dengan cara persediaan kategori A disimpan pada tempa atau wilayah yang tertutup dan keakuratan catatan data persediaannya harus diverifikasi lebih sering.

c. Meramalkan persediaan kategori A harus lebih berhati-hati daripada meramalkan persediaan kategori B ataupun kategori $\mathrm{C}$.

2. Jika perusahaan menggunakan metode analisis $\mathrm{ABC}$, bisa dilakukan dengan menggunakan perhitungan computer agar lebih mudah dalam perhitunganya.

\section{Keterbatasan Penelitian}

Terdapat keterbatasan dalam penelitian ini, adapun keterbatasannya sebagai berikut :

1. Penentuan harga barang yang berubah-ubah dari pemasok menjadikan salah satu kendala dalam penelitian ini.

2. Periode penelitian yang digunakan dalam penelitian ini hanya periode tahun 2019 .

3. Penelitian ini hanya difokuskan pada cabang Gatot Subroto dan tidak keseluruhan persediaan bahan baku yang ada di PT. Dyriana.

\section{Agenda Penelitian Selanjutnya}

Penelitian ini memiliki keterbatasan yang dapat diperbaiki pada penelitian-penelitian selanjutnya. Pertimbangan yang dapat digunakan adalah :

1. Periode yang digunakan dalam penelitian bisa lebih panjang sehingga dapat dibandingkan dengan periode-periode yang diteliti dilihat dari harga yang berubahubah.

2. Dilakukan penelitian dengan mengfokuskan ke seluruh pemakaian persediaan bahan baku yang ada di PT. Dyriana agar dapat lebih efektif dalam perencanaan pembelian bahan baku. 


\section{DAFTAR PUSTAKA}

Afianti, Happy Fauzi Et Al. "Bahan Baku Impor Dengan Metode Abc Analysis Di Pt Unilever Indonesia , Cikarang, Jawa Barat.” : 77-90.

Analisis, Penerapan Et Al. 2015. "Penerapan Analisis Abc Dalam Pengendalian Persediaan Produk Pertanian Pada Ud Mansur Papar Kediri."

Junaidi, Junaidi. 2019. "Penerapan Metode Abc Terhadap Pengendalian Persediaan Bahan Baku Pada Ud. Mayong Sari Probolinggo.” Capital: Jurnal Ekonomi Dan Manajemen 2(2): 158 .

Maharsi, Sri. 2000. "Pengaruh Perkembangan Teknologi Informasi Terhadap Bidang Akuntansi Manajemen.” Jurnal Akuntansi Dan Keuangan 2(2): 127-37.

Maisaroh, Yusrin, Muhammad Rijalus Sholihin, And Sarah Farhana. 2019. “Analisis Pengendalian Internal Persediaan Barang Dagang Pada Cv Pp Lumajang." Prosiding Seminar Nasional \& Call For Paper 0(0): 161-67. Http://Jurnal.Unmuhjember.Ac.Id/Index.Php/Sncp/Article/View/2010.

Rotikan, Gloria Stefanie. 2013. "Penerapan Metode Activity Based Costing Dalam Penentuan Harga Pokok Produksi Pada Pt. Tropica Cocoprima.” Jurnal Riset Ekonomi, Manajemen, Bisnis Dan Akuntansi 1(3): 1019-29.

Sari, Etrik Andaga. 2010. "Pengendalian Persediaan Bahan Baku Kain Grey Dengan Metode Analisis Abc Pada Pt. Primissima Yogyakarta.’Http:// Simki.Unpkediri.Ac.Id. Tanggal Akses 10 Februari 2020.

Suhara, Ade. 2017. "Penerapan Metode Persediaan Probabilistik Untuk Menghitung Kebutuhan Bahan Baku (Studi Kasus Di Pt. Xzy).” Buana Ilmu 1(2): 201-12.

Wibisono, Arief. 2009. "Penerapan analisis ABC dalam pengendalian persediaan produk furniture pada java furniture, Wonosari, Klaten.”: 1-84 http://digilib.uns.ac.id. Tanggal akses 10 Februari 2020. 